\title{
Notes on the vocalizations of Common Scaly Thrush (Zoothera dauma)
}

Peter Boesman

In the following we briefly analyze and compare voice of the different races of Common Scaly Thrush (Zoothera dauma), and Sri Lanka Scaly Thrush (Zoothera imbricata). We also try to quantify the extent of any vocal differences using the criteria proposed by Tobias et al. (2010), as a support for taxonomic review. We have made use of sound recordings available on-line from Xeno Canto (XC).

An overview of song per race, illustrated with sonograms:

aurea/toratugumi

Song is a drawn-out whistle at flat pitch, given at intervals.

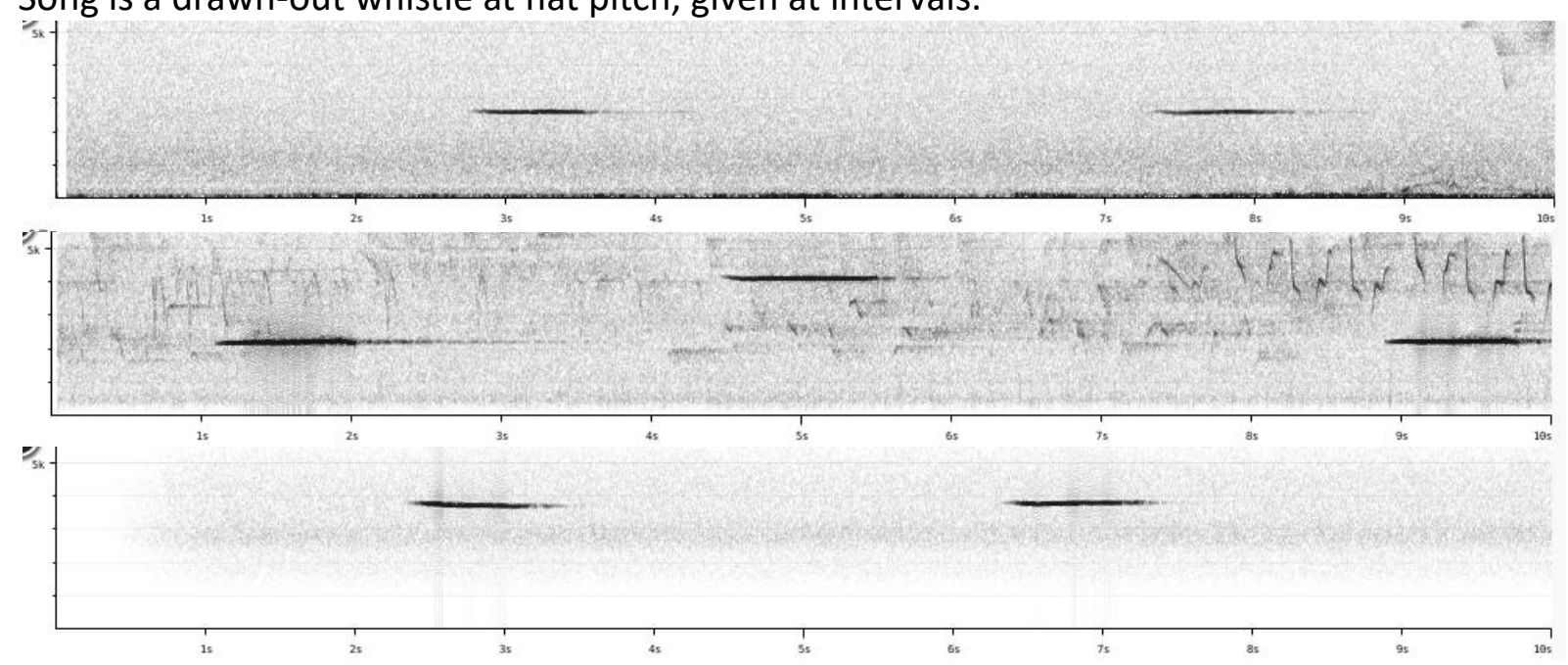

major

Song consists of a sequence of well-spaced different short phrases, which typically include 12 rich low-pitched throaty whistles, sometimes combined with a short high-pitched note.

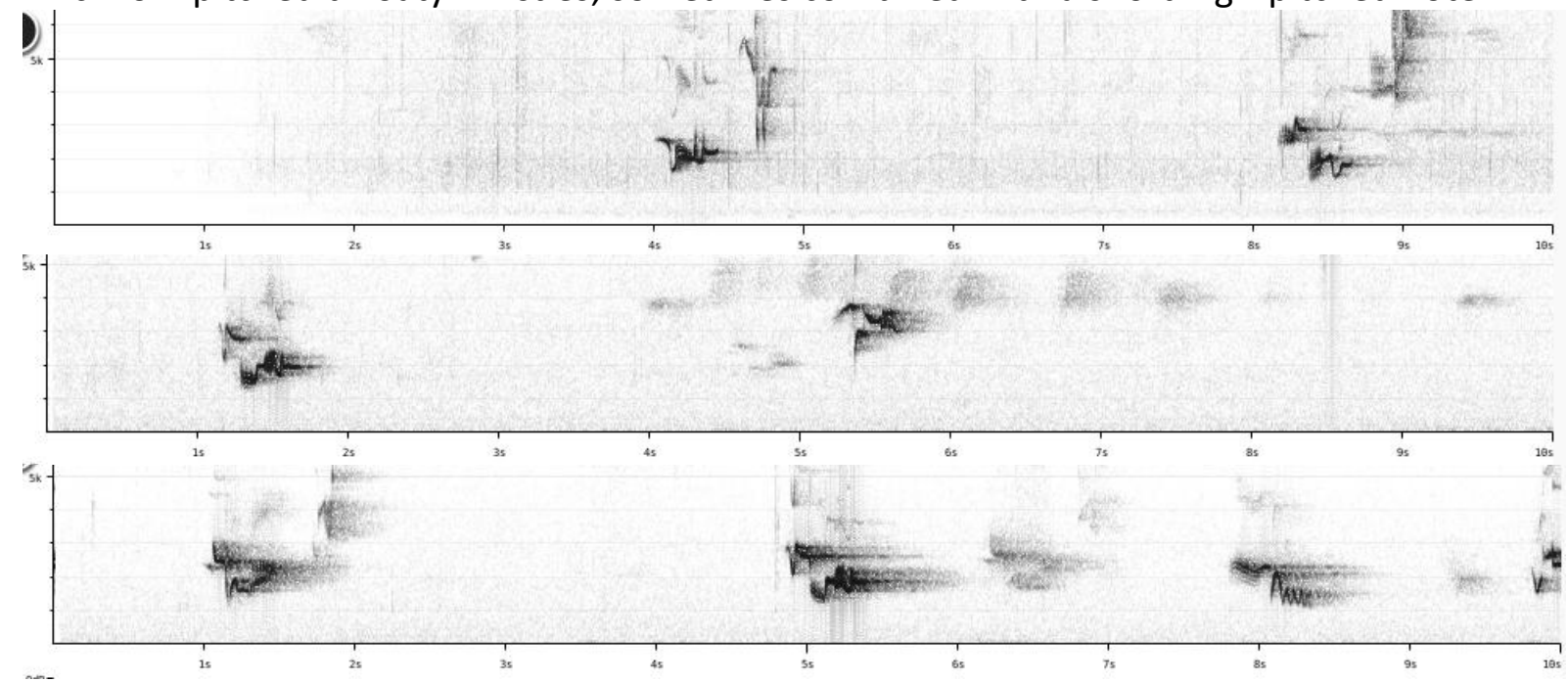



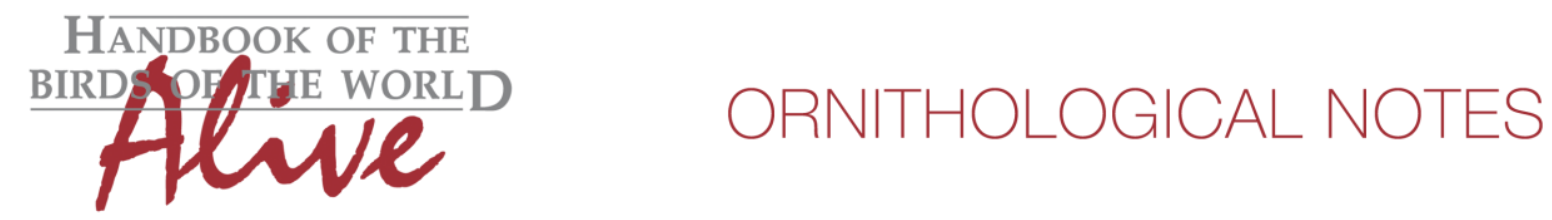

dauma

Song of nominate described as a rather rapid but disconnected series of abrupt, simple, rich notes mixed with squawks, e.g. "pur-loo-trii-lay [repeated] dur-lii-dur-lii [repeated twice] drrdrr-chew-you-wi-iiii [repeated]", sometimes a more languid, continuous stream of notes of same type, "chirrup chwee chueu weep chirrol chup" (HBW Alive, Collar 2013).

This description may be based on the single recording we have found (ML169652):

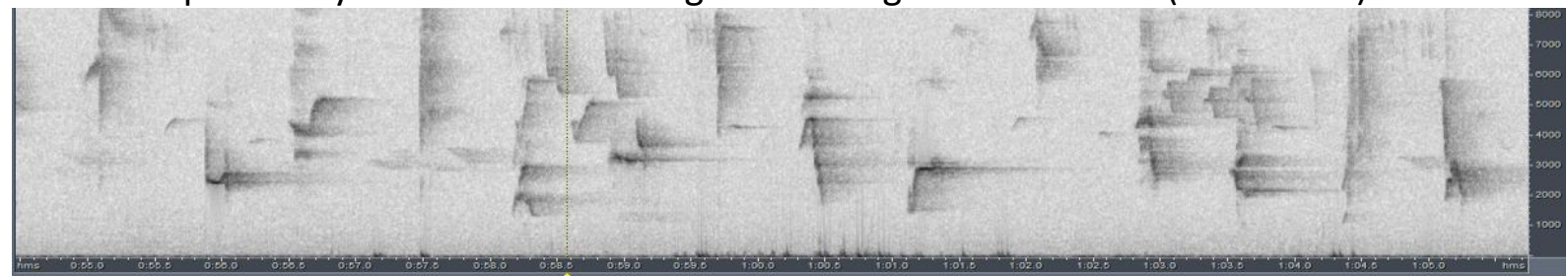

A sonogram depicted in Ripley's guide (Rasmussen et al. 2012) is slower-paced, and the corresponding voice description says: A varied but halting series of short, abrupt, simple disconnected, near-vertical notes, some clear and slurred, some rich and/or burry, others squawking and unmelodious (some combine above qualities, but usually have only 1-3 elements) (pitch 1.5 - 4kHz, note duration 0.1 - 0.3s, 0.5-2 notes/s (suggesting a closer resemblance to race major)

neilgherriensis

Voice apparently 'never directly reported' (Rasmussen et al. 2012)

horsfieldi

Voice is said to be 'a soft monotonous whistle' (MacKinnon et al. 1993), but it is not clear if this is based on the song of birds in that region.

imbricata

Song is a drawn-out slightly down-slurred whistle (duration $0.7-08 \mathrm{~s}, 2.3-2 \mathrm{kHz}$ ).

We have only found a single recording (Warakagoda et al. 2008)

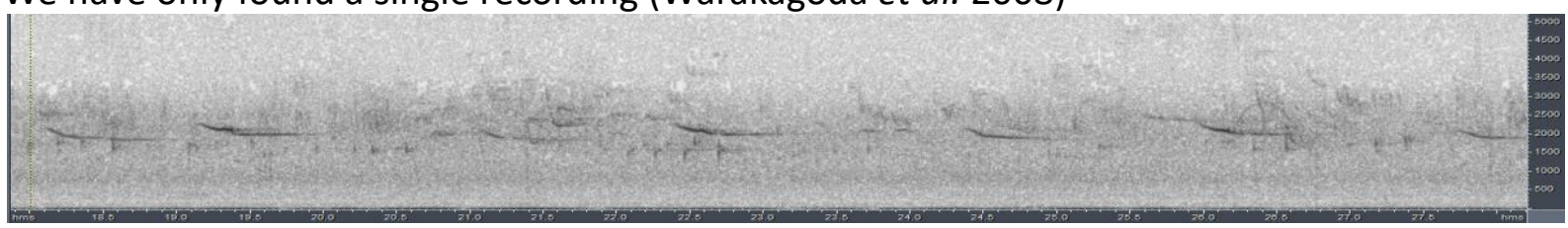

breeding population Taiwan (race ???)

Based on the following recording from June, presumably resident population has a song consisting of a drawn-out whistle at flat pitch.

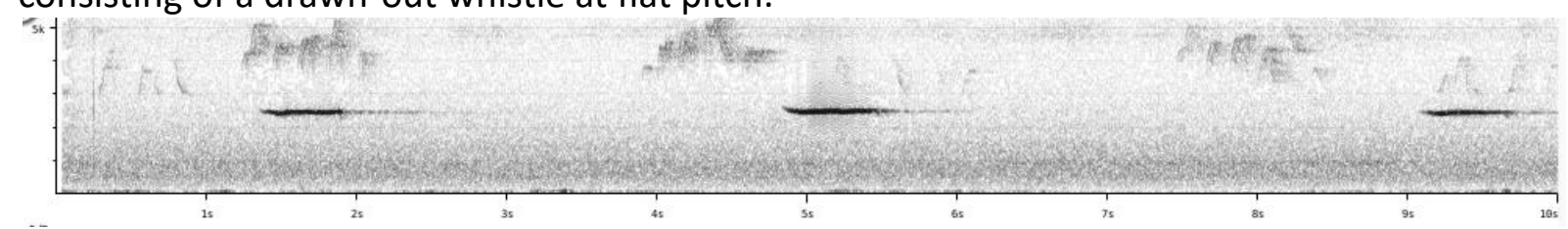

From the above, it is clear that vocally there are several distinct groups, but given that voice of several races is basically unknown, the picture is incomplete. 

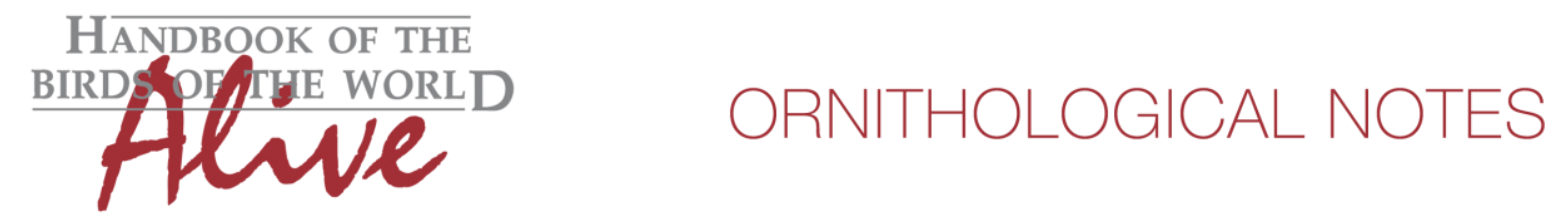

It would seem that vocally, major and dauma are the most distinctive races (both have a song consisting of complex notes vs. the simple whistle of other races (which results in a score 3-4 for larger freq. range, a score 3 for \# of different notes, etc.). In between these two taxa, differences are smaller, but with only 1 available recording (and two somewhat different descriptions) of dauma difficult to assess. It would appear that major has more separated phrases of a few notes, which are more complex, but this is highly speculative.

Song of the breeding population in Taiwan is about identical to aurea/toratuguma. imbricata is slightly different from aurea/toratuguma, in having a down-slurred start of every whistle (but birds in Japan also have occasionally down-slurred whistles, e.g. XC200561, XC285231) (score 2 for larger freq. range).

neilgherriensis and horsfieldi lack information on voice.

This note was finalized on 19th April 2016, using sound recordings available on-line at that moment. We would like to thank in particular the many sound recordists who placed their recordings for this species complex on XC.

\section{References}

Collar, N. (2016). Common Scaly Thrush (Zoothera dauma). In: del Hoyo, J., Elliott, A., Sargatal, J., Christie, D.A. \& de Juana, E. (eds.). Handbook of the Birds of the World Alive. Lynx Edicions, Barcelona. (retrieved from http://www.hbw.com/node/58349 on 19 April 2016).

MacKinnon, J. \& Phillipps, K. (1993). A Field Guide to the Birds of Borneo, Sumatra, Java and Bali. Oxford University Press. Oxford, New York and Tokyo.

Rasmussen, P.C. \& Anderton, J.C. (2012). Birds of South Asia. The Ripley Guide. Second Edition. Lync Edicions. Barcelona.

Tobias, J.A., Seddon, N., Spottiswoode, C.N., Pilgrim, J.D., Fishpool, L.D.C. \& Collar, N.J. (2010). Quantitative criteria for species delimitation. Ibis 152(4): 724-746.

Warakagoda, D. \& Hettige, U. (2008). Birds of Sri Lanka. MP3 sound and image collection. Birdsounds.nl. The Netherlands.

\section{Recommended citation}

Boesman, P. (2016). Notes on the vocalizations of Common Scaly Thrush (Zoothera dauma). HBW Alive Ornithological Note 300. In: Handbook of the Birds of the World Alive. Lynx Edicions, Barcelona. (retrieved from http://www.hbw.com/node/1251751 on 13 October 2016). 